\title{
Demographic Characteristics Among Patients With Chronic Exertional Compartment Syndrome of the Lower Leg
}

\author{
Kelsey M. Rynkiewicz, Lauren A. Fry, and Lindsay J. DiStefano
}

\begin{abstract}
Clinical Scenario: Chronic exertional compartment syndrome (CECS) is a condition related with ischemia of the body's tissue due to increases in intracompartmental pressures, which involves, among other symptoms, pain with exertion. CECS is often overlooked or misdiagnosed due to an ambiguous presentation. Diagnostic accuracy of CECS and subsequent management can be improved when contributing factors are known. Research is lacking on the type of patient most likely to experience CECS, highlighting the need for identification of common demographic characteristics among affected individuals. Clinical Question: What are the common demographic characteristics among patients exhibiting CECS of the lower leg? Summary of Key Findings: Four studies were identified (1 prospective consecutive study, 2 retrospective reviews, and 1 retrospective cohort study) that examined common characteristics among patients with CECS. Conflicting evidence exists on whether CECS is more commonly seen in men or in women. CECS has often been reported in young, active individuals but may present in older populations as well. Soccer, field hockey, lacrosse, competitive running, and speed skating have been associated with an increased likelihood of CECS development. Clinical Bottom Line: Current evidence has identified commonalities in sex, age, and sport participation as characteristics often present among individuals experiencing lower leg CECS. Other factors, such as overuse, trauma, diabetes, and gait mechanics, have also been identified in association with CECS. Further data through future prospective studies will help confirm the type of patient mostly likely to experience CECS. Strength of Recommendation: Grade B evidence exists that certain sex, age, and sport participation demographic characteristics are common among patients with CECS of the lower leg.
\end{abstract}

Keywords: risk factors, clinical presentation, sport participation, exercise-induced, ischemia

\section{Clinical Scenario}

Chronic exertional compartment syndrome (CECS) is a condition involving pain with exertion, likely related with ischemia of the body's tissues as a result of increases in intracompartmental pressures. ${ }^{1-3}$ Most commonly, the lower legs are affected. ${ }^{1,2}$ CECS has been noted in the athletic and exercising populations, often among those who are runners. However, those with more sedentary lifestyles are not immune from the condition. ${ }^{1-3}$ The presentation of CECS symptoms can range in severity with common reports of a dull, achy pain or sensation or feelings of fullness, tightness, cramping, or pressure, which can be accompanied by paresthesia, numbness, and disability or decreased functioning. ${ }^{1,2}$ Onset of symptoms occurs during activity and usually resolves after a period of rest following cessation of the activity. ${ }^{1,2,4}$ Often, based on a pattern of symptoms that may develop, an individual will indicate a specified time frame in which the onset of symptoms occurs following the initiation of exercise. ${ }^{2}$ CECS is often missed due to an ambiguous presentation of symptoms. ${ }^{1}$ Depending on the compartment(s) affected by CECS (anterior, lateral, posterior, and deep posterior) symptoms will relate to the neurovascular and muscular structures in the area. ${ }^{1}$ Differential diagnoses for patients exhibiting leg pain without acute trauma include CECS, medial tibial stress syndrome, stress fracture, tendonitis/myositis, popliteal artery entrapment syndrome, sickle cell disease, radiculopathy/

The authors are with the Department of Kinesiology, University of Connecticut, Storrs, CT, USA. Rynkiewicz (kelsey.rynkiewicz@uconn.edu) is corresponding author. peripheral nerve entrapment, deep vein thrombosis, arterial vascular disease/claudication, or tumor. ${ }^{1}$

Currently, 2 main options exist for the treatment of CECS: surgical intervention or conservative management. Surgical intervention involves releasing of the tissues within the compartment to create more space and decrease the inflammatory effects and pressure buildup during exercise. Conservative management involves modifying behaviors and risk factors to decrease symptoms, allowing for the participation in exercise and activities of daily living. ${ }^{1,2}$

The success of diagnostic accuracy and management of CECS can be improved if the contributing factors of the problem are known, allowing for more focused interventions. ${ }^{4}$ Unfortunately, research is lacking on the type of patient most likely to experience CECS and the common risk factors. ${ }^{5}$ Therefore, the purpose of this paper is to critically evaluate the current research, which identifies the common characteristics, features, and attributes of patients presenting with CECS of the lower leg.

\section{Focused Clinical Question}

What are the common demographic characteristics among patients exhibiting CECS of the lower leg?

\section{Summary of Search, "Best Evidence" Appraised, and Key Findings}

- The literature search was conducted to identify studies investigating predictive factors related with CECS of the lower leg. 
Studies that focused on acute compartment syndrome or CECS of the upper-extremity were excluded.

- Four studies were included: 1 prospective consecutive study, 2 retrospective reviews, and 1 retrospective cohort study.

- One study prospectively investigated 73 consecutive patients with a history of exercise-induced pain. ${ }^{3}$ A total of 36 patients were diagnosed with CECS and were classified into one of the following 4 categories: overuse (18), posttrauma (10), diabetics (4), and other (4). Of these, only 11 patients were active in sport, highlighting the possibility of CECS being more common in the nonathletic population than previously noted.

- There is conflicting evidence regarding sex as a predictor for CECS. In one study, men were identified as having a higher likelihood for CECS diagnosis. ${ }^{6}$ Contrarily, 2 other studies noted CECS as being more prevalent in women. ${ }^{4,5}$

- There is inconsistent evidence regarding the age of patients affected by CECS. One study reported that those who were active and participated in sport were diagnosed with CECS at a younger age, but those who were sedentary and experienced CECS were older. ${ }^{4}$ In a military population, increased age was a risk for CECS. ${ }^{5}$ In addition, it was reported that, in a large general population of patients with exercised-induced lower leg pain, those with CECS were an average of 8 years younger than those without it. ${ }^{6}$

- Two studies looked at the most frequently played sports among those with CECS. In one study, soccer, field hockey, competitive running, and lacrosse were identified. ${ }^{4}$ In another study, soccer was also identified as well as speed skating. ${ }^{6}$

\section{Clinical Bottom Line}

Minimal prospective evidence exists evaluating predictive factors for CECS. ${ }^{3}$ However, retrospective review has identified numerous commonalities in patients exhibiting CECS with regard to sex, age, and sport participation. ${ }^{3-6}$

\section{Strength of Recommendation}

There is level B evidence in support of certain sex, age, and sport participation demographics as common characteristics among those experiencing CECS of the lower leg. Only one study was prospective in nature. ${ }^{3}$ The other retrospective studies included large populations of patients. ${ }^{4-6}$

\section{Search Strategy}

\section{Terms Used to Guide Search Strategy}

Patient/Client group: patients diagnosed with CECS

Intervention: predictive factors and risk factors

Comparison: patients with diagnosed exertional compartment syndrome

Outcomes: Women, high-intensity sports, and younger age

\section{Sources of Evidence Searched}

- PubMed

- EBSCOhost Database

- Google Scholar

\section{Inclusion and Exclusion Criteria}

\section{Inclusion Criteria}

- Articles published in 2000 or later

- Original research

- Articles pertaining to risk of CECS of the lower leg

- Articles mentioning predictive factors of CECS lower leg

- Articles discussing common characteristics among patients with CECS

- Articles published in English language

\section{Exclusion Criteria}

- Articles related with CECS of the upper-extremity

- Articles related with treatment or management of CECS

- Literature reviews, systematic reviews, meta-analyses, case reports, or case series

\section{Results of Search}

Four relevant studies ${ }^{3-6}$ were located and reviewed. The methods of each study were assessed to identify how patient characteristics and demographic data were determined and analyzed.

\section{Best Evidence}

The following studies were identified as the "best" evidence and selected for inclusion in the critically appraised topic. Reasons for selecting these studies were:

- Relevance to the clinical question

- Original research

- Meeting of inclusion and exclusion criteria

\section{Summary of Best Evidence}

Table 1 provides a summary of the relevant studies.

\section{Implications for Practice, Education, and Future Research}

CECS has been reported as a condition that commonly affects young, active individuals. $^{2}$ The condition is often missed or misdiagnosed due to a vague presentation of symptoms. ${ }^{1}$ As the symptoms of CECS are also commonly present in other conditions, CECS is often a diagnosis of exclusion. ${ }^{1}$ However, unlike patients with other conditions such as stress fractures or nerve entrapment, those with CECS are often not able push through activity secondary to their pain. ${ }^{1}$ Minimal research exists evaluating the type of patient most likely to experience the condition, but some evidence ${ }^{3-6}$ has identified commonalities in sex, age, and sport participation among individuals diagnosed with CECS.

Patients younger in age have been reported as having a higher likelihood for experiencing CECS in multiple studies. ${ }^{4,6}$ In one retrospective review that identified cases of CECS from a population experiencing lower-extremity pain during activity, younger athletes with a mean age of 24 years were found to be more likely diagnosed with the condition compared with older individuals. ${ }^{4}$ In the same study, older individuals also presented with the condition, but they tended to be sedentary in their activity levels. ${ }^{4}$ This suggests that while young, physically active individuals are at a 
Table 1 Characteristics of Included Studies

\begin{tabular}{|c|c|c|c|c|}
\hline & Edmundsson et $\mathrm{al}^{3}$ & Davis et $\mathrm{al}^{4}$ & Waterman et al $^{5}$ & De Bruijn et $a^{6}$ \\
\hline Study design & Prospective consecutive study & Retrospective review & Retrospective cohort study & Retrospective cohort study \\
\hline Participants & $\begin{array}{l}\text { - } 73 \text { patients with a history of } \\
\text { exercise-induced pain and } \\
\text { suspicion of CECS were } \\
\text { referred for further evaluation. } \\
\text { - } 63 \text { patients qualified and were } \\
\text { assessed. } \\
\text { - } 36 \text { patients diagnosed with } \\
\text { CECS (average age, } 36 \text { y; } \\
\text { range, } 16-65 \text { y; } 22 \text { women } \\
\text { and } 14 \text { men) }\end{array}$ & $\begin{array}{l}\text { - } 226 \text { patients ( } 393 \text { legs) with } \\
\text { concerns of CECS were } \\
\text { identified. } \\
\text { - } 153 \text { patients diagnosed with } \\
\text { CECS ( } 250 \text { legs; average age, } \\
24 \text { y; range, } 13-69 \text { y } 92 \\
\text { women and } 61 \text { men) } \\
\text { - Average BMI: } 25\end{array}$ & $\begin{array}{l}\text { - } 4100 \text { military members } \\
\text { diagnosed with CECS were } \\
\text { identified using the Defense } \\
\text { Medical Epidemiology } \\
\text { Database ( } 3476 \text { women } \\
\text { and } 624 \text { men). }\end{array}$ & $\begin{array}{l}\text { - } 1411 \text { patients with a history } \\
\text { and physical examine sug- } \\
\text { gestive of CECS who under- } \\
\text { went intracompartmental } \\
\text { pressure testing } \\
\text { - } 698 \text { patients diagnosed with } \\
\text { CECS (median age, } 225 \mathrm{y} \text {; } \\
\text { range, 12-81 y; } 352 \text { women } \\
\text { and } 346 \text { men) }\end{array}$ \\
\hline $\begin{array}{l}\text { Intervention } \\
\text { investigated }\end{array}$ & N/A & N/A & N/A & N/A \\
\hline $\begin{array}{l}\text { Outcome } \\
\text { measure(s) }\end{array}$ & $\begin{array}{l}\text { - Patients were split into groups; } \\
\text { groups were compared for } \\
\text { history, clinical findings, and } \\
\text { postoperative outcome. }\end{array}$ & $\begin{array}{l}\text { - Charts of the patients diag- } \\
\text { nosed with CECS were re- } \\
\text { viewed and data were } \\
\text { collected for demographic } \\
\text { characteristics (age, gender, } \\
\text { and BMI), data regarding } \\
\text { pain, and sport participation. }\end{array}$ & $\begin{array}{l}\text { - Unadjusted IRs were calcu- } \\
\text { lated utilizing multivariate } \\
\text { Poisson regression for risk } \\
\text { factors (sex, age, race, branch } \\
\text { of military service, and rank). } \\
\text { - Adjusted IRRs were calcu- } \\
\text { lated by comparing risk } \\
\text { factors in subcategories } \\
\text { of interest. }\end{array}$ & $\begin{array}{l}\text { - Univariable analysis was } \\
\text { conducted using odds ratios } \\
\text { for predictors of CECS, and a } \\
\text { multivariate analysis was } \\
\text { conducted for variables pres- } \\
\text { ent in }>50 \% \text { of patients from } \\
\text { the univariable analysis. } \\
\text { - A final model was presented as } \\
\text { a nomogram after assessing } \\
\text { discriminative ability and } \\
\text { validity. }\end{array}$ \\
\hline $\begin{array}{l}\text { Main } \\
\text { findings }\end{array}$ & $\begin{array}{l}\text { - CECS patients were split into } 4 \\
\text { etiological groups: overuse, } \\
\text { posttrauma, diabetic, and } \\
\text { other; no differences were } \\
\text { found for age and sex between } \\
\text { groups. } \\
\text { - Only } 11 \text { of the } 36 \text { patients were } \\
\text { active in sport ( } 6 \text { active ath- } \\
\text { letes and } 5 \text { recreational run- } \\
\text { ners); most patients with } \\
\text { CECS were sedentary and } \\
\text { experienced pain with } \\
\text { walking. }\end{array}$ & $\begin{array}{l}\text { - CECS was more prevalent in } \\
\text { women. } \\
\text { - Younger athletes were more } \\
\text { likely to develop CECS. } \\
\text { - Sedentary individuals were } \\
\text { older when CECS developed. } \\
\text { - Those with CECS were more } \\
\text { likely to be involved in sports; } \\
\text { soccer (26), competitive } \\
\text { running (25), lacrosse (18), } \\
\text { and field hockey (16) being } \\
\text { the most frequently played. }\end{array}$ & $\begin{array}{l}\text { - Service members }>40 \text { y old } \\
\text { had } 9 \text { times higher IRR for } \\
\text { CECS than those }<20 \text { y. } \\
\text { - Women had higher IRR than } \\
\text { men. } \\
\text { - White service members } \\
\text { had higher IRR than black } \\
\text { members. } \\
\text { - Army service members had } \\
\text { the highest rates of CECS. } \\
\text { - Junior rank personnel had the } \\
\text { highest IRR for CECS. }\end{array}$ & $\begin{array}{l}\text { - Patients with CECS were an } \\
\text { average of } 8 \text { y younger than } \\
\text { those without CECS; median } \\
\text { age at time of diagnosis was } 25 \text {. } \\
\text { - Men sex was associated with } \\
\text { a higher likelihood of CECS. } \\
\text { - Speed skating and soccer } \\
\text { increased the likelihood of } \\
\text { CECS. } \\
\text { - Running decreased the likeli- } \\
\text { hood of CECS. }\end{array}$ \\
\hline $\begin{array}{l}\text { Level of } \\
\text { evidence }\end{array}$ & 2 & 3 & 2 & 3 \\
\hline $\begin{array}{l}\text { Validity } \\
\text { score }\end{array}$ & N/A & N/A & N/A & N/A \\
\hline Conclusion & $\begin{array}{l}\text { - CECS is multifactorial. } \\
\text { - CECS is more common in the } \\
\text { nonathletic population than } \\
\text { previously recognized. } \\
\text { - Minor trauma or diabetes may } \\
\text { contribute to the development } \\
\text { of CECS. }\end{array}$ & $\begin{array}{l}\text { - Minimal evidence exists to } \\
\text { describe the type of patient } \\
\text { most likely to develop CECS. } \\
\text { - Women, young athletes, and } \\
\text { athletes involved in soccer, } \\
\text { field hockey, and lacrosse are } \\
\text { common sub-populations } \\
\text { among those with CECS. }\end{array}$ & $\begin{array}{l}\text { - Women sex, increased age, } \\
\text { and white race are associated } \\
\text { with higher IRs of CECS. } \\
\text { - For military-specific factors, } \\
\text { junior enlisted rank and } \\
\text { Army service are associated } \\
\text { with higher IRs of CECS. }\end{array}$ & $\begin{array}{l}\text { - Those of a younger age and } \\
\text { men sex are more likely to be } \\
\text { diagnosed with CECS. } \\
\text { - Skating and soccer are asso- } \\
\text { ciated with a higher likelihood } \\
\text { of CECS; increased sport } \\
\text { intensity also appears to be } \\
\text { associated with CECS. }\end{array}$ \\
\hline
\end{tabular}

Abbreviations: BMI, body mass index; CECS, chronic exertional compartment syndrome; IR, incidence rate; IRR, incidence rate ratio; N/A, not applicable.

higher risk for CECS, older individuals with limited activity can still develop CECS. Similarly, a retrospective cohort study ${ }^{6}$ identified 698 patients as being diagnosed with CECS from a population of 1411 patients experiencing symptoms consistent with CECS and also found patients with CECS to be younger (median age, 25 y). ${ }^{6}$ In this cohort, those with CECS were on average 8 years younger than those without the condition. ${ }^{6}$ The oldest patient in the study with CECS was 81 years old with a plateau in prevalence around 50 years of age. ${ }^{6}$ Contrastingly, in a military population examined by Waterman et al, ${ }^{5}$ older age was associated with a higher incidence of CECS. An increase in incidence rate ratios were seen in successive age groups that were identified as $<20,20$ to 24,25 to 29,30 to 34,35 to 39 , and $\geq 40$ years of age. ${ }^{5}$ Those over 40 years had an incidence rate ratio 9 times that of those under 20 years, which may be due to an unknown age-related phenomenon, structural changes from repetitive lower-extremity 
stress, and/or the increased number of older personnel in the military compared with the historically young, active demographic group. ${ }^{5}$ Although conflicting evidence ${ }^{4-6}$ regarding the most common age for CECS presentation exists, it appears that those who are younger are more likely to experience the condition, especially among those who are active. ${ }^{4,6}$

In addition, research suggests that sex is a characteristic that can influence the likelihood of CECS diagnosis. ${ }^{4-6}$ However, the current literature has different opinions on which sex has the higher prevalence of CECS. According to one retrospective review, authors noted significantly higher incidence rate ratios for CECS in women compared with men. ${ }^{5}$ Conflicting studies, such as De Bruijn et al, ${ }^{6}$ provide evidence to suggest that men have a higher likelihood than women. Selection bias may be able to provide an explanation for this result, due to the subjects who were analyzed. For instance, one study had an initial population of more women than men (142 women and 84 men). ${ }^{4}$ Of the 226 patients with concerns of CECS, a total of 153 patients were diagnosed with CECS (92 women and 61 men). ${ }^{4}$ There was no attempt from the researchers to normalize their data, potentially contributing to the conclusion of women being at a greater risk. Unfortunately, only 3 of the 4 articles that were appraised considered sex as a risk factor for CECS. ${ }^{4-6}$ Of those 3, 2 articles reported that women athletes are at higher risk of CECS, suggesting women may be at a greater risk than their men counterparts. ${ }^{4,5}$ Each study analyzed had various subject pools with differing activity levels. This is likely another reason for inconsistent findings on sex as a predictive characteristic for CECS.

Participation in sport has been commonly associated with the development of CECS. According to Davis et al, ${ }^{4}$ athletes involved in soccer, field hockey, and lacrosse were more likely to experience CECS compared with athletes involved in basketball, football, softball, rowing, skating, wrestling, ballet, rugby, fencing, ice hockey, cycling, tennis, and racquetball. In addition, those who were competitive runners (eg, track and cross-country), as well as recreational runners, were also more likely to develop CECS. ${ }^{4}$ De Bruijn et $\mathrm{al}^{6}$ also found participation in soccer, as well as speed skating, to be related with CECS development. There appeared to be an association between higher intensity exercise and CECS. ${ }^{6}$

Aside from age, sex, and sport participation, other factors mentioned in the literature include overuse, trauma, diabetes, and running mechanics. Overuse and diabetes were identified as 2 etiological groups of CECS diagnosis by Edmundsson et $\mathrm{al}^{3}$ in a prospective consecutive study. The study also identified a past history of trauma (ie, substantial injury to the affected leg that resulted in pain and swelling of the extremity) as another contributory factor. ${ }^{3}$ Most traumas identified had occurred years previously with muscle contusions being the most common injury. ${ }^{3}$ De Bruijn ${ }^{6}$ noted the role of previous trauma in CECS presentation stating that cases with unilateral symptoms more often reported a prior pathology than cases with bilateral symptoms. One case-control study has been published identifying gait mechanics as a possible indicator of CECS. Overstride during running and increased dorsiflexion angle at initial contact were exhibited by those who were accurately diagnosed with CECS. ${ }^{7}$ These factors need to be further explored to identify additional components as determinants of CECS.
Due to variations in presentation and multiple differential diagnoses, CECS diagnosis can be delayed. ${ }^{7}$ This has negative implications on patient outcomes as symptoms and disability may persist with unsuccessful management techniques. Subsequently, higher health care costs may be incurred if CECS goes undiagnosed. Understanding one's susceptibility for CECS by utilizing knowledge of common factors associated with the condition can decrease diagnostic time, improve diagnostic accuracy, and initiate treatment to allow for a faster return to sport or activity.

Future research should focus on additional prospective studies to further confirm common characteristics among those diagnosed with CECS as the current research is still controversial. Research regarding specific demographic characteristics is needed as identifying these attributes may improve the likelihood of early and proper diagnosis, leading to better patient outcomes. Although some characteristics such as age and sex are nonmodifiable factors, others such as gait patterns and sport participation can be altered. Interventions (eg, stretching techniques, massage, gait modifications, work to rest ratios, and myofascial release) can be utilized as part of a comprehensive and conservative treatment plan as it may limit the need for surgical intervention. ${ }^{1}$ Programs which attempt to correct certain factors and/or implement conservative management also need to be investigated for effectiveness, allowing for the identification of successful strategies to increase patient success.

\section{References}

1. Vajapey S, Miller TL. Evaluation, diagnosis, and treatment of chronic exertional compartment syndrome: a review of current literature. Phys Sportsmed. 2017;45(4):391-398. PubMed ID: 28952402 doi:10. 1080/00913847.2017.1384289

2. Rajasekaran S, Hall MM. Nonoperative management of chronic exertional compartment syndrome: a systematic review. Curr Sports Med Rep. 2016;15(3):191-198. PubMed ID: 27172084 doi:10.1249/ JSR.0000000000000261

3. Edmundsson D, Toolanen G, Sojka P. Chronic compartment syndrome also affects non-athletic subjects: a prospective study of 63 cases with exercise-induced lower leg pain. Acta Orthop. 2007;78(1): 136-142. PubMed ID: 17453405 doi:10.1080/17453670610013547

4. Davis DE, Raikin S, Garras DN, Vitanzo P, Labrador H, Espandar R. Characteristics of patients with chronic exertional compartment syndrome. Foot Ankle Int. 2013;34(10):1349-1354. PubMed ID: 23669162 doi:10.1177/1071100713490919

5. Waterman BR, Liu J, Newcomb R, et al. Risk factors for chronic exertional compartment syndrome in a physically active military population. Am J Sports Med. 2013;41(11):2545-2549. PubMed ID: 23911700 doi:10.1177/0363546513497922

6. De Bruijn JA, van Zantvoort APM, van Klaveren D, et al. Factors predicting lower leg chronic exertional compartment syndrome in a large population. Int J Sports Med. 2018;39:58-66. PubMed ID: 29126337 doi: $10.1055 / \mathrm{s}-0043-119225$

7. Sugimoto D, Brilliant AN, d'Hemecourt DA, d'Hemecourt CA, Morse JM, d'Hemecourt PA. Running mechanics of females with bilateral compartment syndrome. J Phys Ther Sci. 2018;30:10561062. PubMed ID: 30154600 doi:10.1589/jpts.30.1056 